This item was submitted to Loughborough's Research Repository by the author.

Items in Figshare are protected by copyright, with all rights reserved, unless otherwise indicated.

\title{
Thermal activation Eyring energy approach to characterise the dependence of nanoscale friction on the surface roughness
}

PLEASE CITE THE PUBLISHED VERSION

https://doi.org/10.1016/j.triboint.2020.106532

\section{PUBLISHER}

Elsevier

VERSION

AM (Accepted Manuscript)

\section{PUBLISHER STATEMENT}

This paper was accepted for publication in the journal Tribology International and the definitive published version is available at https://doi.org/10.1016/j.triboint.2020.106532.

LICENCE

CC BY-NC-ND 4.0

\section{REPOSITORY RECORD}

Umer, Jamal, F Saleem, M Asim, M Usman, MS Kamran, K Alam, and Mahdi Mohammad-Pour. 2020.

"Thermal Activation Eyring Energy Approach to Characterise the Dependence of Nanoscale Friction on the Surface Roughness". Loughborough University. https://hdl.handle.net/2134/12570878.v1. 


\title{
Thermal activation Eyring energy approach to characterise dependence of nanoscale friction on surface roughness
}

\author{
J. Umer ${ }^{1,2 *}$, F. Saleem 3 , M. Asim 4 , M. Usman², M. S. Kamran², K. Alam, M. Mohammadpour ${ }^{1}$ \\ ${ }^{1}$ Wolfson School of Mechanical, Electrical and Manufacturing Engineering, Loughborough University, Loughborough, \\ Leicestershire, UK \\ ${ }^{2}$ Department of Mechanical Engineering, University of Engineering and Technology, Lahore 54890, Pakistan \\ ${ }^{3}$ Department of Chemical and Polymer Engineering, University of Engineering and Technology, Faisalabad Campus, \\ Lahore 39161, Pakistan \\ ${ }^{4}$ Ability R\&D Energy Research Centre (AERC), School of Energy and Environment, City University of Hong Kong, \\ Kowloon, Hong Kong \\ ${ }^{5}$ Mechanical and Industrial Engineering Department, Sultan Qaboos University, Postal code 123, Al-Khoud, Sultanate of \\ Oman \\ *Corresponding author: J.Umer@1boro.ac.uk
}

\begin{abstract}
Atomic Force Microscope (AFM) is used to characterise the frictional response of surfaces with varying roughness parameters in dry and in the presence of fully formulated lubricants. The surface roughness has shown to affect nanoscale friction. The characteristics involved the investigation of roughness, small-scale adhesive forces and nanoscale friction using AFM in lateral force mode. The fluid-cell Lateral Force Microscopy (LFM) results at a combination of sliding velocities and normal load are then were used to model thermal activation Eyring energy components approach in conjunction with the relevant continuum contact mechanical mechanics model. The paper shows that a combination of LFM, for dry and fluid-cell LFM and thermal activation Eyring energy barrier approach is a useful tool to explain the effect of surface roughness on nanoscale friction.
\end{abstract}

Keywords: Nanoseale friction; fluid cell LFM; Activation Eyring energy; surface-roughness;

\section{Nomenclature}
$A$
Contact area $\left[\mathrm{m}^{2}\right]$
$C_{F} \quad$ Calibration factor [-]
E Potential barrier $[\mathrm{KJ} / \mathrm{mol}]$
$F_{f} \quad$ Friction $[\mathrm{N}]$
$F_{N} \quad$ Normal contact force $[\mathrm{N}]$
$E_{1} \quad$ Modulus of elasticity of the AFM tip material [Pa]
$E_{2} \quad$ Modulus of elasticity of the sample surface material [Pa]
$E^{*} \quad$ Combined modulus of elasticity $[\mathrm{Pa}]$ 


$\begin{array}{ll}K_{B} & \text { Boltzmann constant }[\mathrm{KJ} / \mathrm{mol} \mathrm{K}] \\ P & \text { Contact pressure [m] } \\ Q & \text { Activation Energy to initiate sliding [KJ/mol K] } \\ R & \text { AFM tip radius [m] } \\ R_{a} & \text { Average roughness in line scan [m] } \\ R_{q} & \text { Root mean square roughness in line scan [m] } \\ R_{p} & \text { Maximum roughness height in line scan [m] } \\ R_{p k} & \text { Reduced peak height roughness in line scan } \\ R_{t} & \text { Maximum height of the roughness in line scan [m] } \\ S_{a} & \text { Average roughness in area scan [m] } \\ S_{p} & \text { Maximum peak height in area scan [m] } \\ S_{q} & \text { Root mean square roughness in area scan [m] } \\ S_{s k} & \text { Skewness } \\ S_{v} & \text { Maximum pit height in area scan [m] } \\ S_{z} & \text { Maximum height in area scan [m] } \\ v_{0} & \text { Operating temperature [K] } \\ v_{0} & \text { Characteristic velocity [m/s] }\end{array}$

\section{Greek Letters}

$\theta$

$\tau$

$v_{1}$

$v_{2}$

$\mu$

$\phi$

$\Omega$
Contact angle $\left[^{\circ}\right]$

Shear stress $[\mathrm{Pa}]$

Poisson's ratio of the AFM tip material [-]

Poisson's ratio of the sample surface material [-]

Coefficient of friction [-]

Shear activation volume $\left[\mathrm{m}^{3}\right]$

Pressure activation volume $\left[\mathrm{m}^{3}\right]$

\section{Abbreviations}




$\begin{array}{ll}\text { AFM } & \text { Atomic Force Microscope } \\ \text { BO } & \text { Base oil } \\ \text { DMT } & \text { Derjaguin-Muller-Toporov } \\ \text { FF } & \text { Fully Formulated lubricant } \\ \text { LFM } & \text { Lateral Force Microscopy } \\ \text { RMS } & \text { Root Mean Square }\end{array}$

\section{Introduction}

The frictional characteristics of the surfaces at the nanoscale are normally different from macroscale and most of the macroscopic friction laws are not applicable at the nanoscale [13]. The macroscopic frictional characteristics law, pioneered by Amontons in 1699 [4], relates friction with normal load through the coefficient of friction. According to Amontons's law [4], the friction force is independent of the area of contact, which was later improved to the asperity contact area to include actual asperities coming into contact [5]. However, for nanoscale friction, many different parameters influence the asperity scale friction including surface morphology, humidity, contact area, sliding velocity, AFM probe radius, and stiffness [6-9]. The nanoscale frictional response in the presence of lubricant measure through atomic force microscope, fluid cell Lateral Force Microscopy (LFM), introduces further complexity in asperity level frictional characterisation [3,10-19].

An automotive lubricant consists of $10-15 \%$ additives and $85-90 \%$ base oil. The chemical additives include anti-wear, dispersants, friction modifiers, oxidation and corrosion stabiliser, and detergents [20,21]. The presence of additive in lubricants make a complex interaction with other additives and surface [15,22-26]. To develop a fundamental understanding of the nanotribological behaviour of lubricants and functioning on engineering surfaces, fluid cell LFM is widely reported in the literature [14,27-32].

Bhushan [6] studied friction, indentation, lubrication, surface morphology and adhesion at the nanoscale using atomic force microscopy. They have found that friction is high when measured in a humid environment. The friction measured using different tip radii showed that friction increases with the tip radius which was associated with the higher meniscus force for a larger tip in AFM measurement. It was also determined that friction measured at the nanoscale is smaller than the measurements conducted at macro/microscales. The friction measured at higher loads also induces plastic deformation due to AFM probe ploughing through the asperities. Maharaj and Bhushan [27] investigated the frictional characteristics of WS2 and MoS2 nanotubes at the nanoscale through use of AFM. They studied surface morphology, scan size and orientation of nanotube on friction. They have found that the variation in topography strongly influences the measured friction at nanoscale. The topography effect is mainly due to collision and ratcheting effect, the function of asperities slope, observed for AFM probe sliding on surface. Maharaj and Bhushan [7] investigated nano and microscale frictional characteristics of nano-objects using AFM and ball on a flat 
tribometer respectively. The study also included measurements in the presence of fluid and dry environment. The found that the friction is strongly dependent on the roughness, contact area and adhesion. Nikhil [33] studied the dependence of scale on adhesion and friction at nano and microscale contact conditions using AFM. The AFM probe with $0.58 \mathrm{~N} / \mathrm{m}$ of stiffness and tip radii of 30-50 $\mathrm{nm}$ was employed. It was observed that the friction was higher when measured for the larger scanned area. They have also found that sliding velocity strongly influences the nanoscale friction. The nanoscale friction and adhesive forces are strongly dependent on the surface roughness and contact pressure.

There is a requirement of energy to initiate and continue sliding motion. This requirement of energy is even required in the presence of lubricant to overcome frictional losses. Many different models explain and relate those frictional losses to quantifiable energy parameters. The thermal activation cage model is one of the important energy models that includes contact pressureand sliding velocity. Briscoe and Evens [34] used a smooth and atomically flat surface to investigate the frictional response of Langmuir-Blodgett [35] monolayer of the solution of carboxylic at various contact pressure, sliding velocities and contact temperature. The Langmuir-Blodgett monolayer was prepared on atomically flat mica surface by dipping it in carboxylic solution and thereafter the monolayer was compressed to ensure stabilisation. They also used the Eyring theory to develop a thermal activation energy model that includes contact pressure, sliding velocity and contact temperature. They found that there is a requirement of energy for the molecules toto initiate and continue sliding motion due to the presence of neighbouring molecules. Ewen et al [36] investigated the frictional characteristics of hematite surface in the presence of organic friction modifiers in n-hexadecane. They used molecular dynamic simulations for non-equilibrium analysis. The simulation study included the investigation of shear rate, contact pressure and slip length and their effect on the measured friction. The study included a higher shear rate ranging from $10^{8}$ to $10^{11} \mathrm{~s}^{-1}$ and it was observed that the slip length increased with the increase of contact pressure and shear rate. They also found that higher coverage of h-hexadecane increases slips length and friction.

Tambe and Bhushan [37] developed a mathematical model to investigate the effect of sliding velocity $(1 \mu \mathrm{m} / \mathrm{s}$ to $10 \mathrm{~mm} / \mathrm{s})$ and contact area $\left(2\right.$ to $\left.25 \mu^{2}\right)$ on the nanoscale friction. They used dry and surface in presence of lubricant. The found that the nanoscale friction varies with sliding velocity and the trend of nanoscale friction with sliding velocity reverses at critical velocity. This critical velocity depends on the interaction of surface with lubricant. Chong and Rahnejat [11] Used alloys steel and nickel Silicon carbide to investigate Bing application avoiding energy theory in the presence of fully formulated $10 \mathrm{~W} 40$ and besides using an atomic force microscope in little force mode. They also used cross-hatched honed, representing a typical IC engine cylinder liner surface, to evaluate effect of surface roughness on nanoscale friction. They measured nanoscale friction using a probe with stiffness of 0.35 $\mathrm{N} / \mathrm{m}$ and tip radius $60 \mathrm{~nm}$. The nanoscale frictional characteristics, for fully formulated lubricants, was then modelled through application of Eyring thermal activation energy approach to determine pressure, shear and thermal components. Furlong et al [38] also used Prandtl-Tomilinson [39] to investigate the effect on the shape of energy barrier due to nonsinusoidal constant force applied at an atomic scale. The developed methodology was then 
validated through nanoscale friction measurement through an atomic force microscope. This also helped to explain the sliding friction and its dependence on the sliding velocity and contact temperature. Spikes and Tysoe [40] used an Eyring [41] energy and PrandtlTomlinson [39] models to explain the boundary friction. This can also be used to explain the wear and tribochemistry during boundary friction for tribological contact conditions. Umer et al $[15,42]$ studied the nanoscale frictional characteristics of base oil and fully formulated oil using an atomic force microscope in lateral force mode using DNP 10 AFM probe with a stiffness of $0.12 \mathrm{~N} / \mathrm{m}$. They generated antiwear tribofilm on the surface through the application of sliding strip tribometer $[15,17]$. They also experimentally determined the nanoscale elasticity of the tribofilm and steel surface by using AFM operating in ramping mode [43] by using RTESPA AFM tip with a stiffness of $200 \mathrm{~N} / \mathrm{m}[44,45]$. They used a thermal activation energy approach based on the cage like model to determine Eyring energy parameters. They found that pressure and shear activation energies were negative for the base oil due to higher adhesive forces, but these parameters were positive for fully formulated oil in the presence of ZDDP based tribofilm. They also determined that the ZDDP based antiwear presents a higher load-bearing capacity in comparison to the base oil. The energy barrier height was higher for ZDDP based tribofilm, which also explained the increase in friction associated with antiwear tribofilm.

Bouhacina et al [46] used Lateral Force Microscopy (LFM) to evaluate friction at nanoscale for silica wafers, 3-ehtoxysilane with polyacetylene grafted and silica wafer with 3ethodysilate grafted. They used a sliding velocity ranging from $10^{2}$ to $10^{4} \mathrm{~nm} / \mathrm{s}$ and three probes of the stiffness of $0.38 \mathrm{~N} / \mathrm{m}, 0.58 \mathrm{~N} / \mathrm{m}$ and $0.12 \mathrm{~N} / \mathrm{m}$. The nanoscale experimental results were then modelled using the Eyring energy model and relevant Eyring energy parameters were evaluated. They used characteristics velocity of $100 \mathrm{~m} / \mathrm{s}$ and $0.2 \mathrm{~nm}^{3}$ estimated shear activation volume. They also determined activation volume and dependence of shear strength and barrier height on the sliding velocity. It was also determined that the measured Eyring energy parameters were independent of the stiffens of AFM probe. Ku et al [47] investigated an ultra-thin adsorbed boundary layer and its frictional characteristics for ultra-smooth counteracting bodies. They used Squalane and Hexadecane fluids to describe the measured friction through the use of Thermal activation Eyring energy approach. Müser [48] used the Prandtl-Tomlinson model to evaluate the effect of velocity and temperature on the nanoscale friction. The Langervin equation was numerically solved through the use of molecular dynamics simulation. The effect of temperature and sliding velocity were modelled for up to $2^{\text {nd }}$ and $6^{\text {th }}$ order respectively. They found that temperature dependence shows a transition from linear to coulombic at intermediate temperatures. They also found that friction is relatively independent of sliding velocity at lower temperatures, but it varies considerably with the sliding velocity at high temperatures. Buzio et al [12] investigated the applicability of friction laws for dry and lubricated contact conditions using AFM. They used an AFM probe with cantilever stiffness of $0.3 \mathrm{~N} / \mathrm{m}$ and squalene and Octamethylcyclotetrasiloxane ectamethylciclterasilxane (OMCTS) were used as lubricants. They found that the lubricant contacts at the nanoscale were relatively accurate to model through Amontones law and dry contacts through power law. They also investigated and determined various energy 
parameters through modelling of nanoscale friction for lubricated contacts using Eyring energy model.

The literature review shows that nanoscale frictional characteristics of engineering surface and lubricants are widely used to understand the physical mechanism of friction. In contrast to the macro scale, the friction measured at nanoscale depends on the contact area, sliding speed, adhesion, humidity and surface morphology. Therefore, the nanoscale frictional characterisation requires a careful selection of experimental protocols to ensure repeatability. The presence of lubricant on the surface under the AFM probe makes it even more complicated and to develop a fundamental understanding of nanotribological behaviour, a friction model including a combination of applied pressure, shear and temperature is required. Therefore, comprehensive energy models based on transition state theory and Thermal activation energy barrier approach provides an opportunity to include a combination of these parameters. Application of thermal activation energy barrier approach for commercial lubricants on engineering surfaces, as well as the effect of surface roughness on nanoscale friction are widely reported in the literature. This study uses a combined approach to investigate the effect of surface roughness on nanoscale friction and then use of Thermal activation Eyring energy approach to understand individual contribution form pressure, shear and temperature on nanoscale friction are not hitherto reported in the literature.

\section{Thermal activation Eyring energy model}

The thermal activation Eyring energy model, based on the cage like model as reported by Briscoe and Evans [49], was used to model nanoscale frictional characteristics measured through Atomic Force Microscope (AFM) in Lateral Force Mode (LFM). The application of the thermal activation Eyring energy model requires determining the actual contact pressure and shear strength which can only be determined by measuring the contact area. The contact area at the nanoscale can be determined by using one of the continuum contact mechanics models.

The contact area in the LFM measurements is widely modelled through Maugis [50], Derjaguin [51], Johnson et al [52], Bradley [53], and Hertzian Theory [54]. All of these contact mechanics models are used when adhesive forces are non-negligible except the Hertzian contact theory. The Hertzian contact mechanics model is applicable when adhesive forces are not negligible. The current study includes measurement of nanoscale friction in the presence of lubricants that results in negligible adhesion. Therefore, the applicability Hertzian contact mechanic model is valid in line with $[16,42]$.

Therefore, for nanoscale friction measurement in the presence of lubricants, the Hertzian contact mechanics model can be used to determine the contact radius (r) as:

$r=\left(\frac{3 R F_{N}}{4 E^{*}}\right)^{1 / 3}$ 
where, $F_{N}$ is the applied the normal load $F_{N}$ is applied during the AFM experiment and $R$ is the experimentally determined tip radius of the AFM probe used. $E^{*}$ is the combined elastic modulus including Aluminium sample and silicon nitride tip and calculated as [55]:

$E^{*}=\left(\frac{1-v_{1}^{2}}{E_{1}}+\frac{1-v_{2}^{2}}{E_{2}}\right)^{-1}$

The contact area can be determined as:

$A=\pi r^{2}$

The contact pressure is determined as

$P=\frac{F_{N}}{A}$

The shear stress is evaluated as

$\tau=\frac{F_{f}}{A}$

\subsection{Eyring activation potential cage model}

Thermal activation Eyring energy cage-like model is used to explain the boundary friction and lubrication for the surfaces interacting during sliding motion. According to this approach, there is a need for energy to initiate and continue sliding motion to overcome the energy barrier present due to neighbouring molecules. It is also assumed that the average time to overcome the energy barrier for single molecules follows a Boltzmann distribution [41]. This energy barrier due to neighbouring molecules will be required to be overcome by all molecules during motion. The schematic of the energy barrier height is shown in Figure 1. The energy barrier $(E)$ is a function of energy to initiate sliding motion $(Q)$, pressure activation energy $(P \Omega)$ and shear activation energy $(\tau \phi)$. 


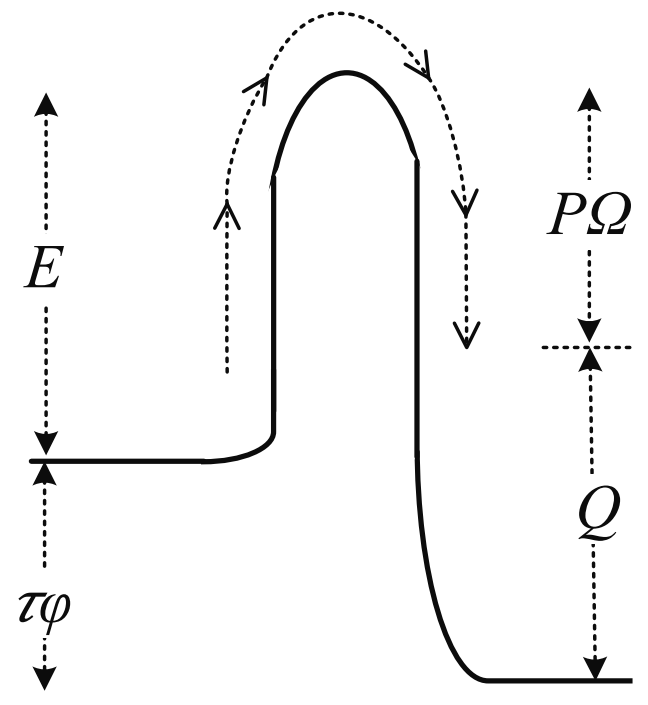

Figure 1: Thermal activation Eyring energy barrier height

The energy barrier height increases with the applied contact pressure and energy required to initiate and continue sliding motion, whereas it decreases with an increase in shear activation energy that can be described as:

$E=P \Omega+Q-\tau \varnothing$

where $\varnothing$ is the shear activation volume and $\Omega$ is the pressure activation volume. Depending on the thermodynamic equilibrium during sliding motion, the activation energy components can decrease or increase and hence results in negative or pressure activation energy components $[11,42,49][56-58]$. The shear activation energy components can be described by the as $[42,49]$ :

$\tau \emptyset=(Q+P \Omega)+K_{b} T \ln \left(\frac{v}{v_{0}}\right)$

where $v$ is the sliding velocity, $T$ is the temperature and $K_{b}$ is defined as the Boltzmann constant. The constant, $v_{0}$ is the characteristics velocity and estimated by the taking product of molecules lattice constant of $0.2 \mathrm{~nm}$ and vibration frequency of $10^{11} \mathrm{~s}^{-1}$. The characteristics velocity is estimated to be $20 \mathrm{~m} / \mathrm{s}$. Thermal activation Eyring energy parameters calculated through the use of this estimated characteristics velocity are relatively insensitive to characteristics velocity [49].

The equation (6) can be rearranged to represent shear stress as a function of contact pressure and sliding velocity as $[42,49]$ :

$\tau=\frac{\Omega}{\varnothing} P+\tau_{0}$

$\tau=\frac{K_{b} T}{\emptyset} \ln v+\tau_{1}$ 
where, $\Omega$ is the pressure activation volume, $\varnothing$ is the shear activation volume, $P$ is the applied contact pressure. The parameters $\tau_{1}$ and $\tau_{0}$ are shear stress at a constant velocity and pressure respectively and evaluated as $[11,42]$ :

$$
\begin{gathered}
\tau_{1}=\frac{P \Omega-K_{b} T \ln v_{0}+Q}{\emptyset} \\
\tau_{0}=\frac{Q+K_{b} T \ln \left(\frac{v}{v_{0}}\right)}{\emptyset}
\end{gathered}
$$

The shear stress is plotted against logarithmic of sliding velocity and a linear relation is determined that helped in finding the $\left(K_{b} T / \varnothing\right)$ using equation (10). With known values Boltzmann constant and temperature, the shear activation volume can also be determined. Similarly, equation (9) is used to plot shear stress against contact pressure and slope $(\Omega / \varnothing)$ for a linear trend line was determined. The pressure activation volume, $\Omega$, is then determined with already calculated values of shear activation volume. The activation energy to initiate and continue sliding motion can be determined using equation (10). Equation (7) can also be re-written in terms of coefficient of friction as

$\mu=\tau_{0} / P+\Omega / \varnothing$

The stress activation length, also termed as coherence length, can be calculated as

$l=\varphi / A$

where $\varphi$ is shear activation volume and $\mathrm{A}$ is the contact area determine through Hertzian contact mechanics model

\section{Experimental Procedure}

The experimental procedure adopted to prepare surface specimens, measurement of topography, and nanoscale friction through the use of an Atomic Force Microscope (AFM) operating in Lateral Force Mode (LFM).

\subsection{Preparation samples}

The surface sample used in this study was a commercial-grade Aluminium alloy which is quite commonly used in engine applications [31,59]. Two surface specimens were prepared, a ground surface and a polished surface. The ground surface represented surface morphology after grinding without any further surface treatment. Whereas, the polished surface was prepared by using polisher to attain a mirror finish. The roughness parameters measured through AFM for both samples are given in the experimental results. A commercially available Shell Helix Ultra Extra fully formulated 10W40 is used in this study. The current study focuses on the effect of surface roughness on thermal activation Eyring energy barrier and relevant parameters when measured through topography dependent nanoscale friction. Therefore, the study is restrained for only one type of lubricant on two different surface specimens with different morphology. The samples were cleaned using petroleum ether before each nanoscale friction measurement in line with [16,42]. 


\subsection{Lateral Force Microscopy}

The asperity level friction at the nanoscale was measured using Atomic Force Microscope (AFM) in lateral force mode by using Veeco Dimension 3100 [29,44,60-66]. The friction was measured for dry surfaces without the presence of lubricant and in the presence of lubricant for both surface samples. To keep meniscus away from the AFM tip and avoid capillary adhesion, a fluid cell holder was employed. The schematic of the fluid cell AFM holder and AFM is shown in Figure 2. The laser source transmits laser directly to the back of the cantilever and the signal is collected at the quadrant photoreactor. The in-plane motion is controlled through the piezoelectric scanner by a feedback control loop.

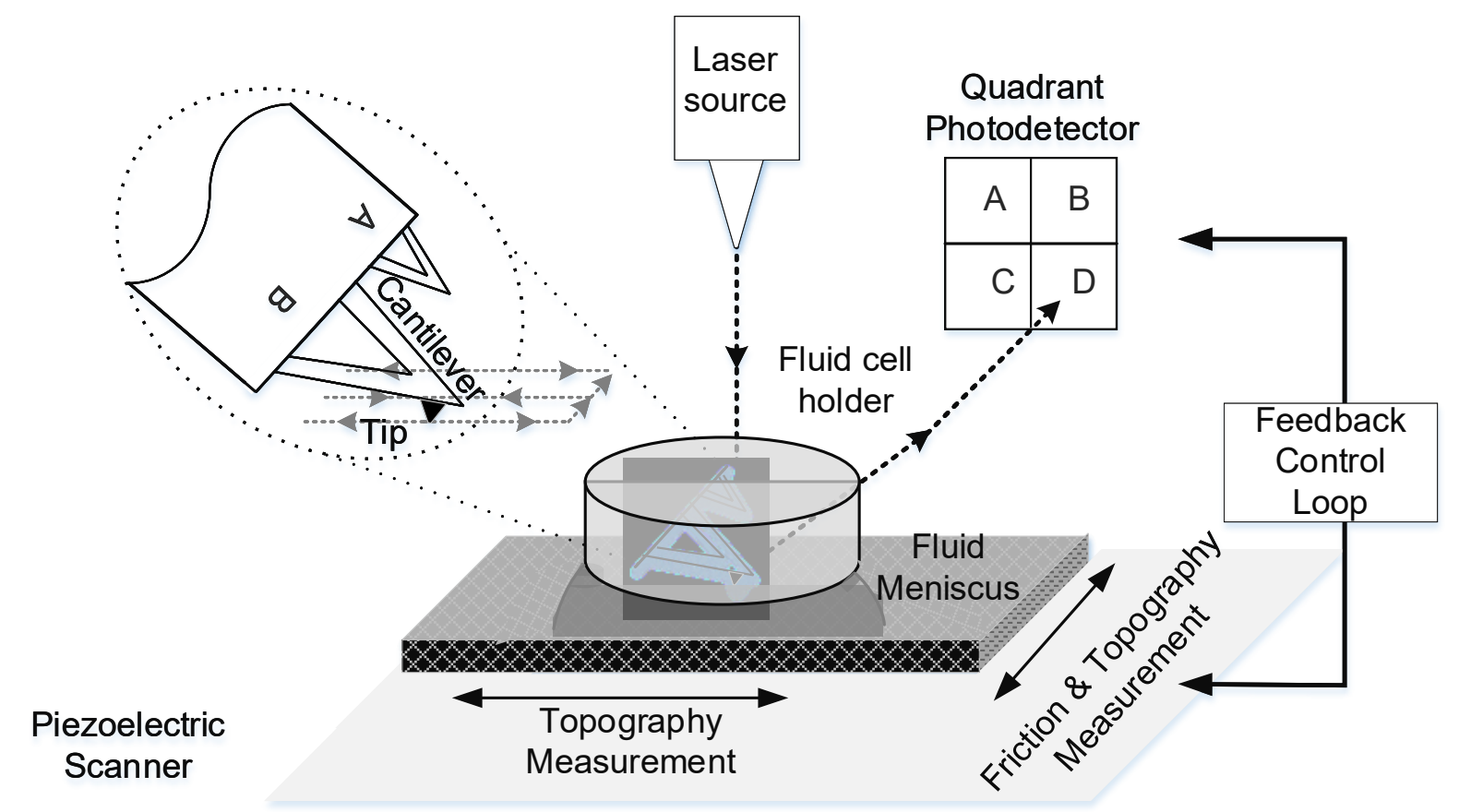

Figure 2: Schematic of Fluid cell nanoscale friction measurement

Trace minus retrace (TMR) method was employed to measure nanoscale friction. In the TMR method, the AFM tip scans perpendicular to the direction of tip cantilever [60]. The continuum contact mechanic models require the use of AFM tip radius which was measured experimentally by scanning of a sample with known surface morphology, TGT1 characteriser (NT-MDT). The TGT1 characteriser has a sharp surface featured of up to $0.5 \mu \mathrm{m}$ heights at a $3 \mu \mathrm{m}$ periodic spacing. The AFM probe for friction measurements was scanned on TGT1 characteriser over a $10 \times 10 \mu \mathrm{m}^{2}$ scanning area using $0.25 \mathrm{~Hz}$ scanning frequency. The scanned image of the TGT1 characteriser and subsequently the production of tip profile is shown in Figure 3. The tip radius is then measured by modelling through a best circular fit to estimated tip profile as shown in Figure 3 b). The tip radius was estimated to be $51 \pm 5 \mathrm{~nm}$ for the current study. 


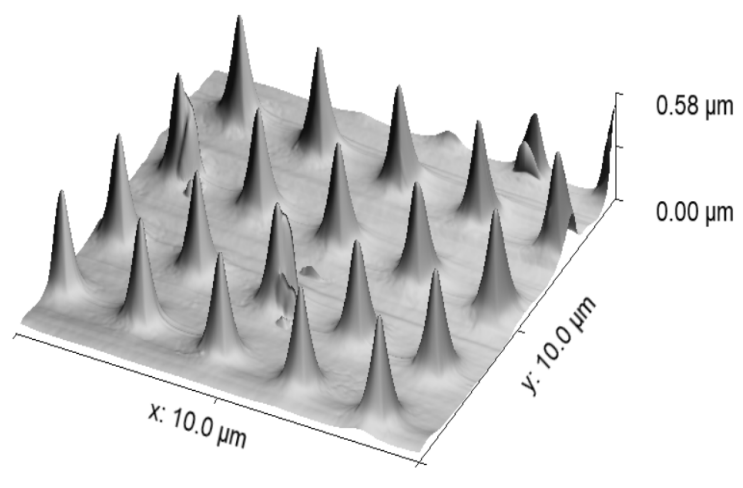

a)

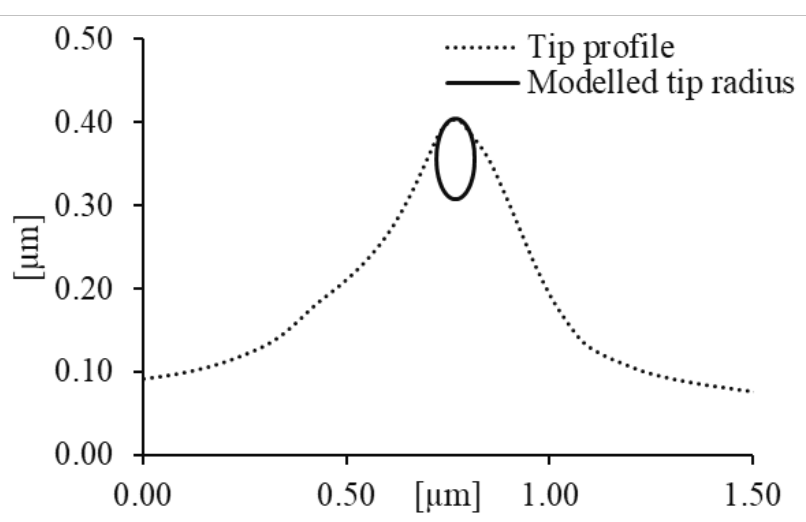

b)

Figure 3: a) Scanned image of TGT1 characteriser and b) estimation of the tip profile and tip radius

A non-conductive Bruker tip B of DNP-10 with a nominal spring constant of $0.12 \mathrm{~N} / \mathrm{m}$ was used for topography and friction measurement. The testing was conducted by using a new AFM probe for each measurement. The lateral response of the AFM probe was calibrated by using a blind calibration procedure in line with $[17,64,67,68]$. The measurement accuracy is strongly linked to the calibration of the frictional response of tip in use [69]. The blind calibration required scanning of new AFM probe on a monolithic silicon nitride sample with a known friction coefficient of $0.19[11,44,65]$. The surface specimens were scanned to measure topography before the measurement of friction in dry conditions. To calibrate, a $1 \times$ $1 \mu \mathrm{m}^{2}$ the area was selected on the silicon nitride calibration sample. The calibration was performed with a scanning frequency of $2 \mathrm{~Hz}$ and a sample array of $256 \times 256$ data points. All of the measurements were conducted at $50 \pm 5 \% \mathrm{RH}$ and $20 \pm 2^{\circ} \mathrm{C}$ of controlled operating conditions. The AFM probe sensitivity was determined by measuring the slope of the forcedistance curve by operating AFM in ramping mode. This sensitivity was then used to covert applied load in units of a volt to physical units in Newtons. The friction was also measured in units of volts and then calibration factor, $C_{F}$, for range of applied loads was determined using $[64,65]$ :

$$
C_{F}=\frac{F_{f}[\mathrm{~V}]}{F_{N}[\mathrm{nN}] \times 0.19}
$$

The best polynomial function was curve fitted for measured friction for a range of applied loads. This calibration factor provides the frictional response of the AFM probe. The friction was then measured for specimen using an equation:

$F_{f}[n N]=\frac{F_{f}[V]}{C_{F}}$

The friction is measured for the specimen for a scanning area of $5 \times 5 \mu \mathrm{m}^{2}$ for a sampling size of $256 \times 256$ data points. The purpose of using a larger area was to ensure the contribution of roughness to be observed in nanoscale frictional characteristics. The friction measurement was always completed after the topography scanning of a specimen. The initial 
topography scan before friction measurement also helped in the selection of relatively flat area as a sharp change in surface affects the nanoscale friction measurements. The topography data was processed by levelling image through plane level rotate. This levelling operation subtracts a mean plane from data and rotates the image to make it a plane [70]. The roughness parameters were then measured for line scan and area scan. The waviness in line scan was further filtered from roughness by using a cut-off length of $1 \mu \mathrm{m}$. The dry friction, in absence of any lubricant, was measured for the specimen and thereafter lubricant was carefully added to the confined region of AFM probe and specimen. A wet-AFM holder was always used for measurements conducted in the presence of lubricants to keep forces due to capillary action away from the AFM probe scanning area [18].

\section{Results and Discussion}

The results for the topography scans for polished and ground specimens for dry surfaces, in the absence of lubricant, are shown in Figure 3. The topography images indicate that the distribution of height is larger for a ground sample as shown in Figure 3 a) and b). The topography data was levelled through rotation and waviness was filtered with a cut off length of $1 \mu \mathrm{m}$. The line scan of the sample shows the distribution of peaks and valleys across the sample size of $5 \times 5 \mu \mathrm{m}$ as shown in Figure $3 \mathrm{c}$ ). 


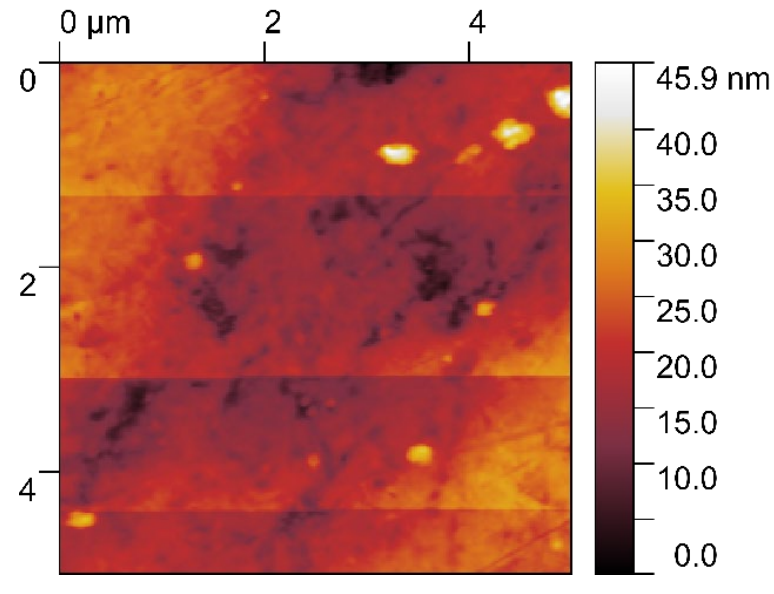

a)

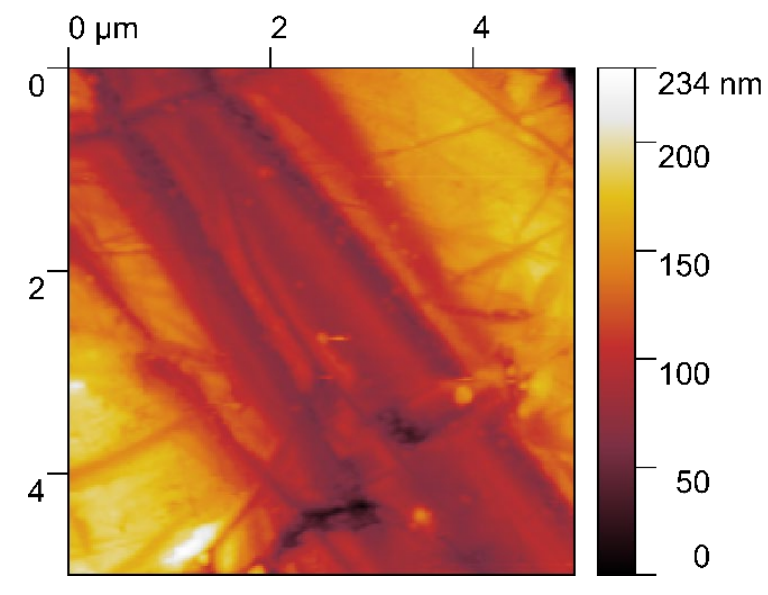

b)

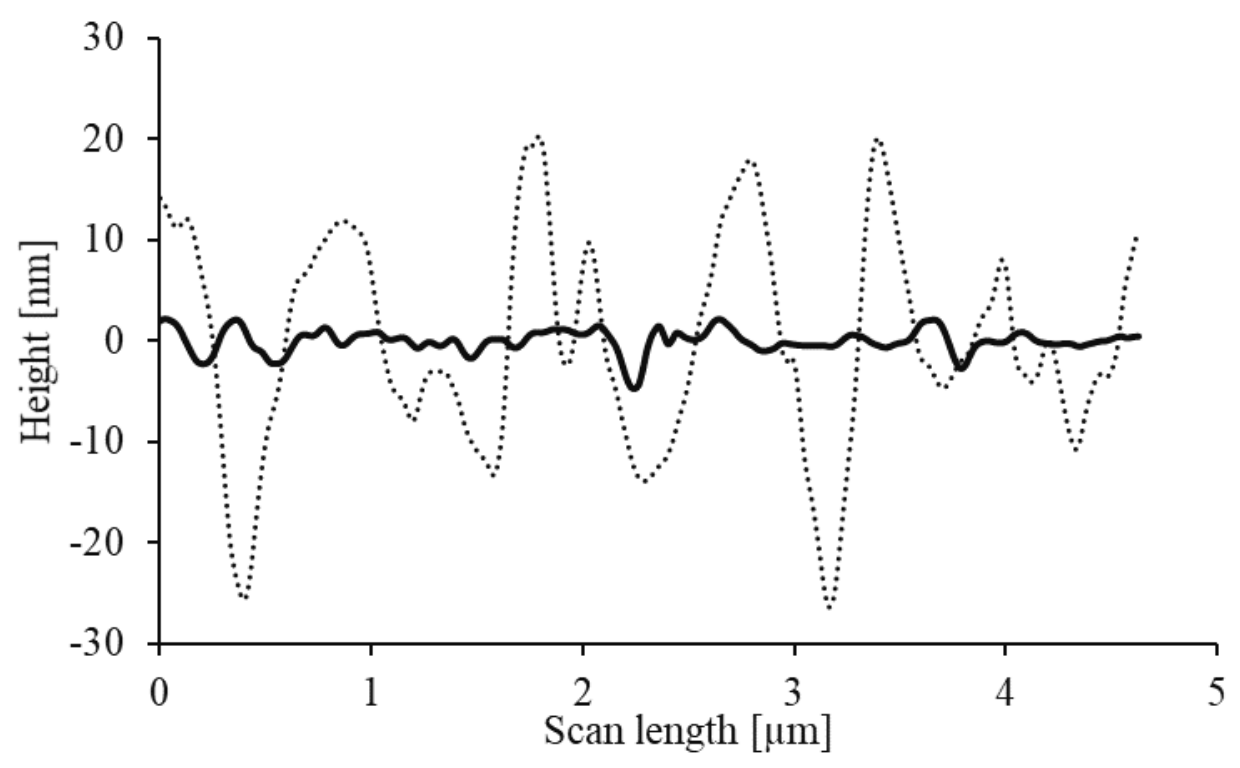

c)

Figure 4: Topography data for a) area scan of polished, b) area scan of ground specimen and c) line scan for both samples

The topographical parameters calculated from area scan including average roughness, RMS roughness, maximum peak and pit height, and maximum height are shown in Figure 4 a). Whereas, Figure 4 b) shows the average roughness, RMS roughness, and maximum roughness height calculated from the line scan. The roughness parameters quantitative analysis shows that the roughness parameters measured for the polished surface are 5 to 10 times less than the ground surface. These variations in parameters are significantly higher to affect nanoscale friction measured at asperity level through AFM in lateral force mode. 


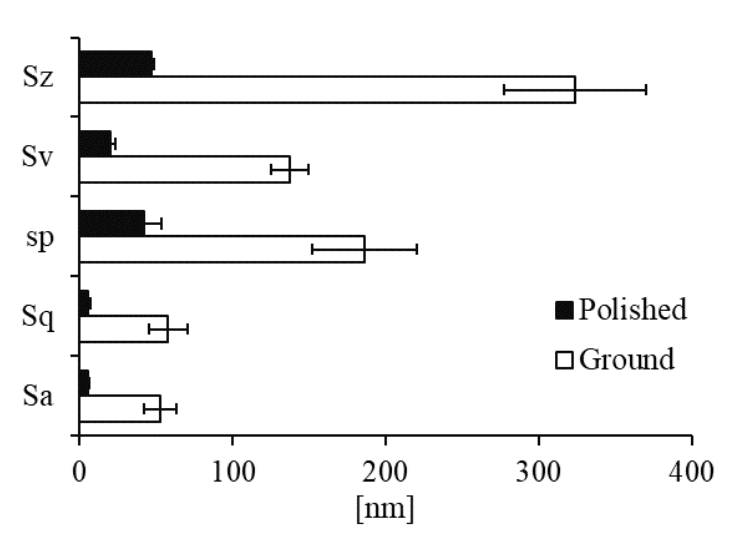

a)

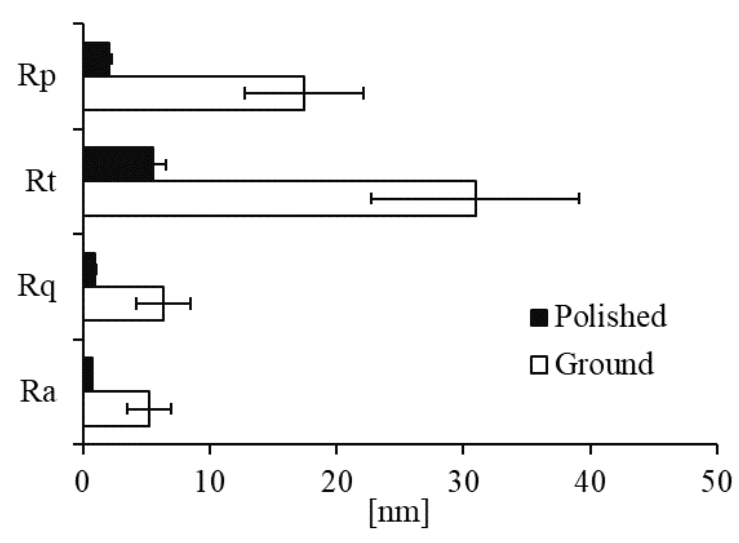

b)

Figure 5: Comparison of roughness parameters for ground and polished specimen for a) area scan and b) line scan

The topographical measurements followed by measurement of asperity level friction in a dry environment, in the absence of lubricant. The AFM measurement was always carried out after cleaning samples with petroleum ether. The dry friction was measured at three different locations with a scanning area of $5 \times 5 \mu \mathrm{m}^{2}$ for $256 \times 256$ data points array for each specimen. The nanoscale friction was measured with a scanning speed of $2 \mathrm{~Hz}$ representing a scanning velocity of $10 \mu \mathrm{m} / \mathrm{s}$. The nanoscale measured friction for dry samples, in absence of lubricant, for polished and ground specimens are shown in Figure 6 a) and Figure 6 b) respectively. The coefficient of friction measured for the polished Aluminium surface is noted to be 0.16 and for ground surface was 0.19 . It is also shown that standard error of measurement for the polished specimen is relatively less in comparison to the ground surface. The friction is clearly dependent on the surface morphology as shown in Figure 6 and more widely reported in the literature $[6,7,12,27,33]$. 


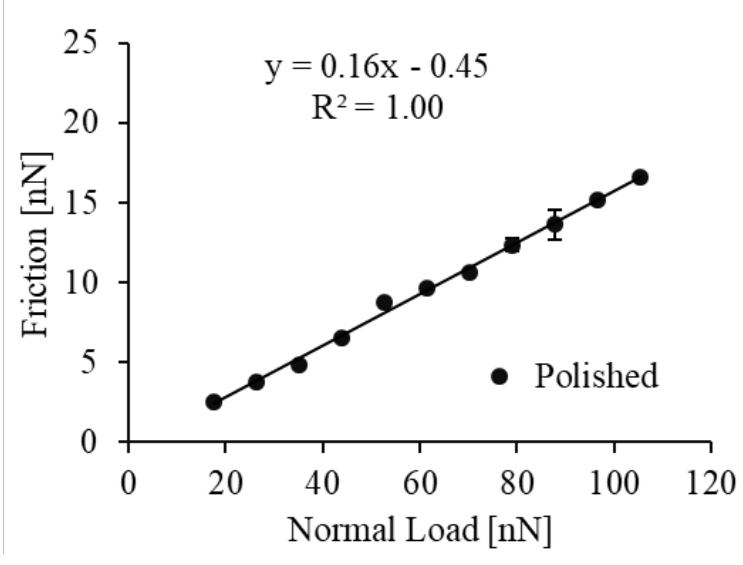

a)

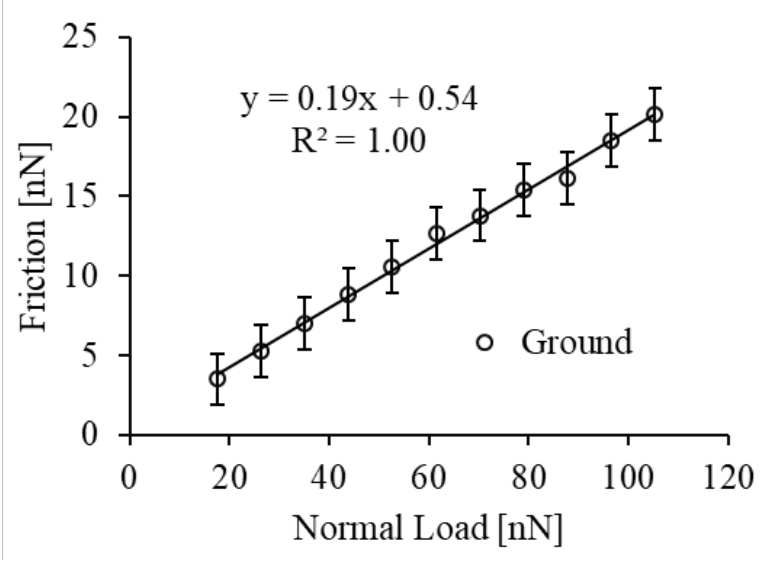

b)

Figure 6: Friction measured at various loads for a) polished and b) ground surfaces in the absence of lubricant

The force-distance curve is widely used to determine AFM probe sensitivity and adhesive forces at the confined region of the AFM probe and surface $[2,3,44,71]$. The force-distance curve analysis is performed using AFM in ramping mode. The roughness variation on the force-distance curve was negligible. The adhesive force measured in the presence of lubricant as shown a red line in Figure 7 is negligible in line with $[11,42]$. Whereas, the adhesive forces measured for a dry surface is calculated to be $16.29 \mathrm{nN}$.

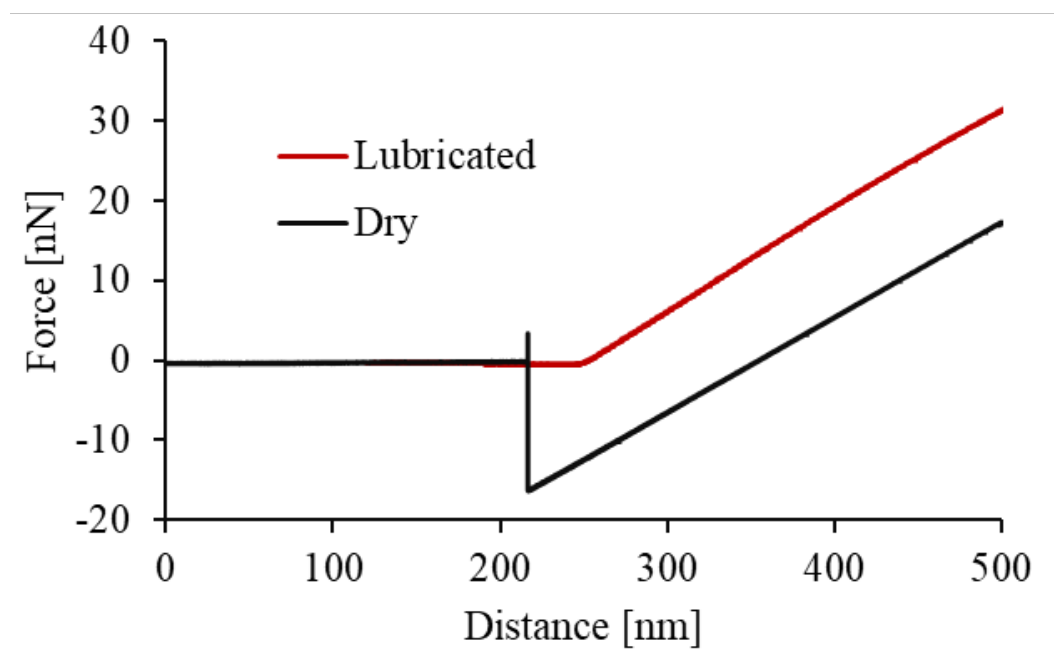

Figure 7: Force-distance curve for lubricated and dry surface

After asperity level friction measurement for dry surface and evaluation of adhesive forces, the lubricant sample was carefully added at the confined region of the AFM probe and surface. The fluid cell nanoscale was completed for scanning velocities ranging from $0.5 \mathrm{~Hz}$ to $3 \mathrm{~Hz}$ that is equivalent to $5 \mu \mathrm{m} / \mathrm{s}$ to $30 \mu \mathrm{m} / \mathrm{s}$. AFM is widely used to study accurately the dependence of friction on low sliding velocities [72] and the selection of sliding velocities were made in line with the range of sliding velocities used by Brisco and Evans [49] and also $[11,19,42,73,74]$. The analysis was completed at a normal applied load of $52.2 \mathrm{nN}, 66.1 \mathrm{nN}$ 
and $80 n N$. The DNP-10 tip B AFM probe used in this study applied contact loads of $20-$ $110 \mathrm{nN}$. The intermediate loads were selected for Eyring energy analysis to ensure the application of enough loads to study the behaviour of surface and lubricant at conjunction. The lower loads could result in false engagement [75] and at higher loads, there is possibility of lubricant draining out of the confined region of AFM probe and surface due to high contact pressures. The decrease in values of friction is observed to be changing with the applied load, i.e. increases with the applied load. However, the friction measured for lubricant on the ground surface is relatively less changing with the applied load in comparison to the ground surface. Similarly, the friction is decreasing with sliding velocity for both specimens in line with [37,49], but the ground surface shows a steeper trend in comparison of polished surface in the presence of a lubricant. It can be concluded that friction is higher at low sliding velocity but with further increase in sliding velocity ground surface is more effective in reducing friction in comparison to the polished surface. The standard error of measurement is also less in case of a polished surface in the presence of lubricant which agrees to the trend observed for dry surfaces.

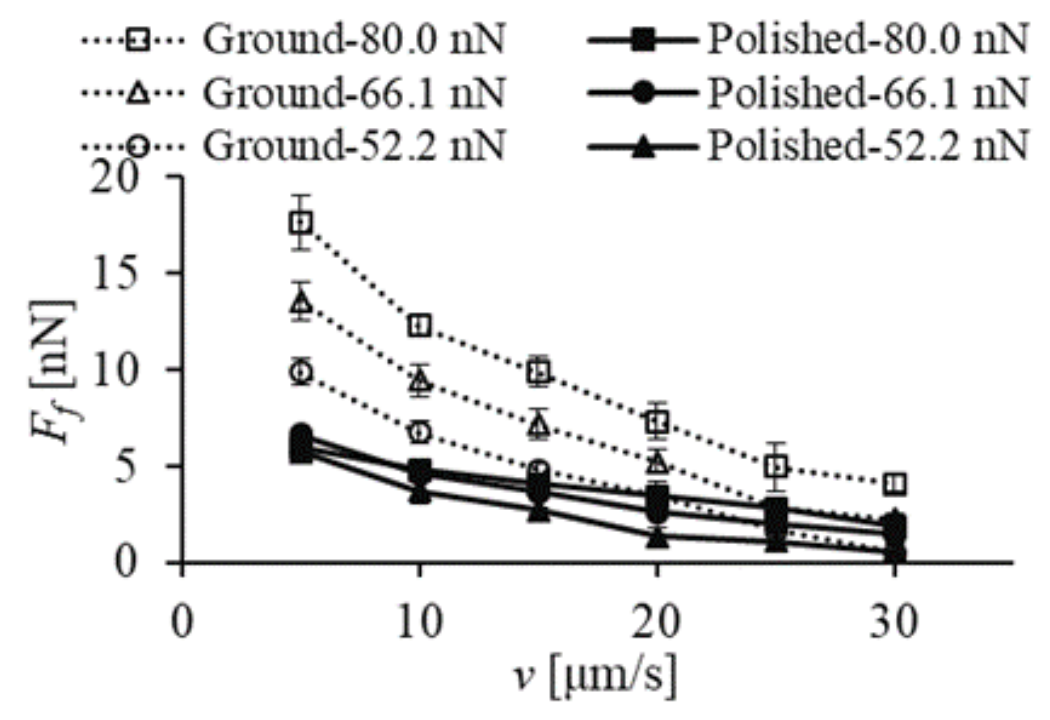

Figure 8: Friction vs sliding velocity for ground and polished surface in the presence of lubricant

The equivalent Hertzian contact pressures for a range of applied load were 2.3 $G P a, 2.5 G P a$ and $2.7 \mathrm{GPa}$ for the applied load. The average tip radius calculated through the TGT1 characteriser was measured to be $51 \pm 5 \mathrm{~nm}$ and bulk properties of Aluminium elastic modulus of $69 \mathrm{GPa}$ was used. The shear stress was determined by using equation (5) and contact area determined through Hertzian contact model in line with [16,67]. The variation of shear stress against the logarithmic of sliding velocity for ground and polished surfaces is shown in Figure 8. A linear trend line is also best fitted to the for shear stress and logarithmic velocity to determine slope in line with $[42,49]$. It is observed that the slope is decreasing with sliding velocity for both samples in line with [49]. However, the slope is observed to be significantly higher for the ground surface in comparison to the polished surface. 


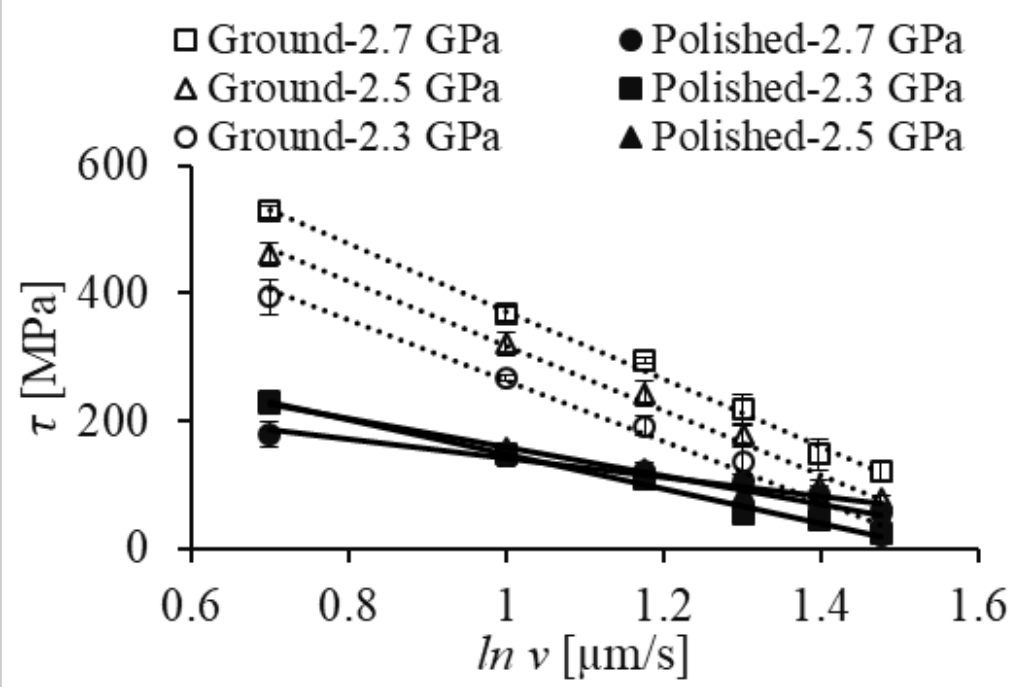

Figure 9: Shear stress variation with logarithmic of sliding velocity for ground and polished surface in the presence of lubricant

The thermal activation Eyring energy parameters, based on the energy barrier $[11,42,49]$, were then evaluated using the procedure explained in section 2.1. The parameters are evaluated using a characteristic of $v_{0}=20 \mathrm{~m} / \mathrm{s}$. the pressure and shear activation energy components are shown in Figure $10 \mathrm{a}$ ) and Figure $10 \mathrm{~b}$ ) respectively. The shear and pressure activation energy components in the thermal activation Eyring energy approach can be negative due to the nature of the relationship between friction and logarithmic sliding velocity as originally described by Briscoe and Evans [49] and later in [11,42] as well as [56$58]$.

The pressure activation can be interpreted as the ability of molecules to withstand loads, i.e. the load-bearing capacity of lubricant boundary film $[19,49,56]$. Therefore, a higher value of pressure activation energy would be able to provide a better separation between mating surfaces during sliding [76]. The pressure activation energy shows a slight increase with sliding velocity for both lubricant samples, which shows an indication of improvement of the load-bearing ability of the lubricant with sliding velocity. This increase of pressure activation energy with sliding velocity can potentially be explained, for an AFM probe and sample confined region, based on a transiting to the hydrodynamic regime of lubrication from boundary film in line with $[13,42,47]$. The negative values of pressure activation energy for all measurements show the presence of adhesive forces and the values are getting more negative with an increase of contact pressure. This is due to the pressing of AFM probe against oil at higher loads, approaching towards the surface, therefore the adhesion is higher at higher loads. This dependency of pressure activation energy on the applied contact load is higher for a polished surface. Therefore, the ground samples show the presence of enough lubricant even at higher loads. 


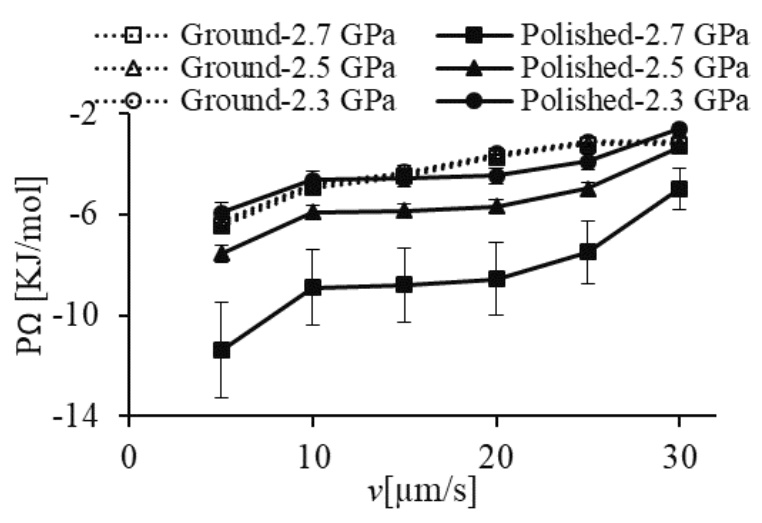

a)

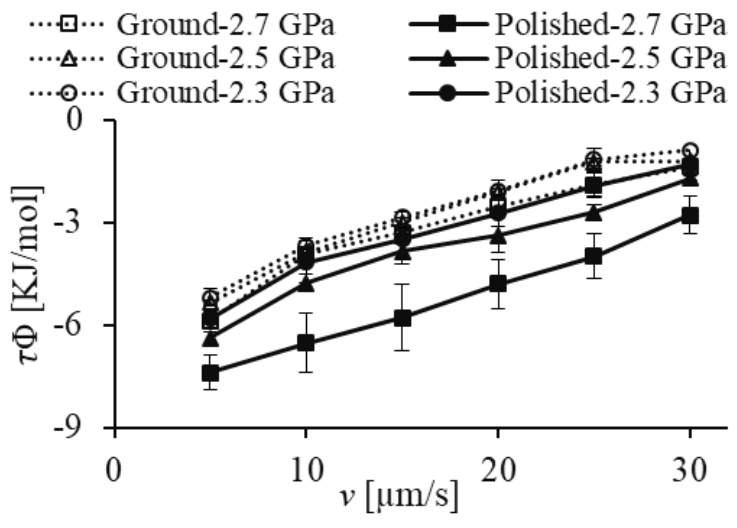

b)

Figure 10: a) Pressure activation energy and b) shear activation energy against sliding velocity and contact pressure

The required energy to initiate sliding motion is termed as the shear activation energy [11]. The energy required to initiate sliding motion is increasing with the sliding velocity as shown in Figure 10 b). The shear activation energy values remain negative for all tested loads and sliding velocities, and this is associated with the presence of adhesive forces at the confined region of the AFM probe and surface [19,56]. The shear activation energy observed to be increasing with the sliding velocity, thus showing that the lubricant is effective in reducing adhesive force at higher sliding velocities. Similarly, with the increase of normal load for lubricant on the polished surface also increases the shear activation energy component as shown in Figure $10 \mathrm{~b}$ ). This can be explained as the lubricant entrainment is increasing with the contact load at the AFM probe-surface conjunction [42,56]. The variation in shear activation energy for the lubricant sample on the ground surface shows the insignificant variation with contact pressures and sliding velocities for the testing conditions selected in this study.

The stress activation length for ground and polished samples is shown in Figure 9 as determined by using equation (13). The coherence length can be described as the molecules, liquid segments, or dislocation that moves during the sliding process in nanoscale friction measurement as reported in $[42,77]$. This is also interpreted as the restructuring of molecules to form entropically cooled boundary layers [77]. The shear force also induces molecular ordering during sliding motion [78]. The restructuring of molecules due to shear is due to the relative motion of the AFM probe against the sample. The shear characteristics, at nanoscale contact conditions measured through AFM, of the surface depends on the surface morphology due to nanoscale friction dependence on the surface morphology $[69,73,79]$. Therefore, the entropically cooled boundary layer, formed due to shear of lubricant molecules, should also be a function of surface roughness's parameters. 


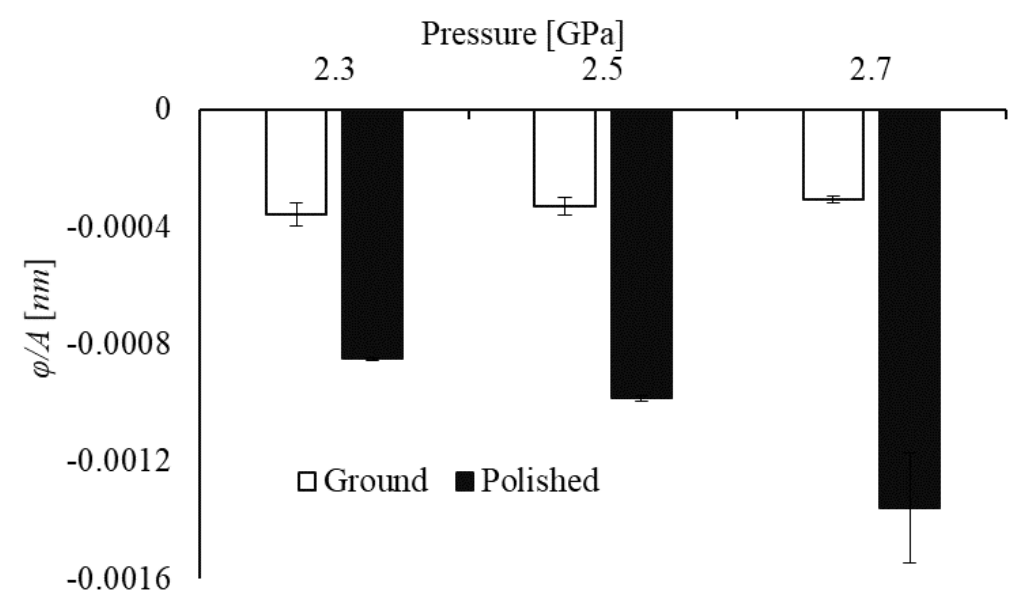

Figure 11: Coherence length for FF lubricant on ground and polished specimen

The results for FF lubricant on the ground and polished surface for the coherence length measured at asperity level contact conditions are shown in Figure 9. The negative values for the coherence length is due to the relation of friction with sliding velocity, which has resulted in a negative slope as determined from shear stress and logarithmic sliding velocity (Figure 9) and [42]. The coherence length measured for FF lubricant on the polished surface is observed to be higher than on the ground surface. The coherence length showed an increasing trend with the applied load, contact pressure, for lubricant on the polished surface. Whereas, the coherence length is observed to be smaller and stays relatively constant with further application of contact load. Therefore, it can be concluded that a polished surface provides a better ability to align molecules, hydrocarbon polymeric chains, and additives molecules present in the lubricant, as shown through the stress-induced coherence length in Figure 9. There is also a possibility that a mixture of long and small molecules, present in FF lubricant additives $[13,80]$, are experiencing harsher conditions when measured on the ground surface in comparison to the polished surface as observed in Figure 6 and Figure 8.

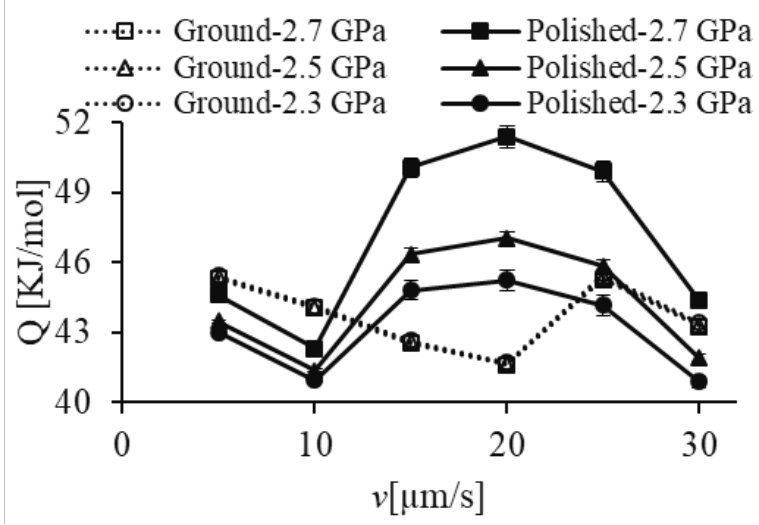

a)

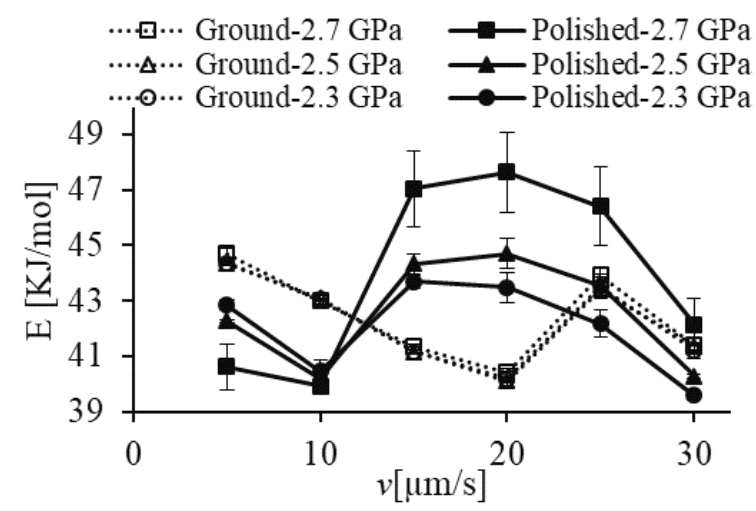

b)

Figure 12: a) Energy to initiate and continue sliding motion and b) energy barrier height at different loads and sliding velocities 
Finally, Figure 12 a) and Figure 12 b) shows the variation of energy required to initiate and continue sliding motion, $Q$, and energy barrier height $E$ respectively. The energy required to initiate and continue sliding motion is relatively consistent for FF lubricant on the ground surface whereas, for polished surface, the energy required to initiate and continue sliding motion is low at low sliding velocity, but it increases with the sliding velocity and then levels off. At the intermediate sliding velocity, this energy parameter is highest at the contact pressure of $2.7 \mathrm{GPa}$ for the polished surface. The value of $Q$ has also shown a decrease with sliding velocity for ground surface followed a similar trend of friction decreasing with the sliding surface for ground surface [35,77]. The energy barrier, E shows a decreasing trend for the ground surface with the sliding velocity with a slight increase at $25 \mu \mathrm{m} / \mathrm{s}$. The contact pressure does not show any significant effect on the ground surface for energy barrier height, whereas, for a polished surface, the energy barrier height increases with the contact pressure. The energy barrier height is higher at low sliding velocity, but it decreases with further increase in sliding velocity for ground surface; a similar trend was also observed for friction with sliding velocity for ground surface.

\section{Conclusions}

The current study focuses on the effect of surface morphology on nanoscale friction in dry conditions and in presence of commercial FF lubricant measured through use of AFM in lateral mode at different contact pressures and sliding velocities. The specimen was prepared to ensure that the surface average and RMS roughnesses are distinctly different, which has resulted in different nanoscale friction in line with $[33,78,81]$. The fluid cell LFM measurements, for samples in presence of FF lubricant were also modelled by using the Thermal activation Eyring energy approach based on energy barrier theory $[19,49,77]$. The energy parameters were then evaluated to investigate the effect of roughness on Eyring energy parameters including shear and pressure activation energies, energy to initiate and continue sliding motion, and energy barrier height.

The shear and pressure activation energies have been observed to be negative for the tested conditions of applied loads and sliding velocities. The negative values of these energy parameters are due to the relationship between friction and sliding velocity $[19,42,49]$ and indicate the presence of surface energy at the confined contact of AFM probe and specimen $[11,19]$. These parameters also have shown an increasing trend with sliding velocity and contact pressure, thus indicating the effectiveness of lubricant in the reduction of adhesive forces at a higher velocity and contact load for the polished surface. The ground surface, however, showed insignificant variation with contact load. The coherence lengths determined for surfaces indicate that the polished surface can align polymeric chain molecules better than the ground surface. The contact pressure has observed to increase energy barrier height for the polished surface.but, for the ground surface it insignificantly altered the energy barrier height.

\section{Acknowledgements}


The first author acknowledges the financial support provided to him by the University of Engineering and Technology Lahore under the faculty development programme to conduct this research at Loughborough University. The use of Atomic Force Microscope at the Woflson School of Mechanical, Electrical and Manufacturing engineering, Loughborough University is also acknowledged.

\section{Reference}

[1] Mo, Y., Turner, K.T., Szlufarska, I., "Friction laws at the nanoscale", Nature, 2009, 457 (7233), pp. 1116-1119.

[2] Bhushan, B., Handbook of micro/nanotribology, CRC Press, 1999.

[3] Bhushan, B., Introduction to tribology, 2nd ed., John Wiley \& Sons, 2013.

[4] Amontons, G., "De la resistance causée dans les machines", Mem. Acad. R. A, 1699, pp. 275-282.

[5] Bowden, F.P., Tabor, D., The friction and lubrication of solids, Clarendon Press, Oxford UK, 1950.

[6] Bhushan, B., "Nanotribology and nanomechanics", Wear, 2005, 259 (7), pp. 15071531 .

[7] Maharaj, D., Bhushan, B., "Friction, wear and mechanical behavior of nano-objects on the nanoscale", Materials Science and Engineering: R: Reports, 2015, 95 pp. 1-43.

[8] Carpick, R.W., Salmeron, M., "Scratching the Surface: Fundamental Investigations of Tribology with Atomic Force Microscopy", Chemical Reviews, 1997, 97 (4), pp. 1163-1194.

[9] Carpick, R.W., Ogletree, D.F., Salmeron, M., "Lateral stiffness: A new nanomechanical measurement for the determination of shear strengths with friction force microscopy", Applied Physics Letters, 1997, 70 pp. 1548.

[10] Kim, B.H., Mourhatch, R., Aswath, P.B., "Properties of tribofilms formed with ashless dithiophosphate and zinc dialkyl dithiophosphate under extreme pressure conditions", Wear, 2010, 268 (3-4), pp. 579-591.

[11] Chong, Rahnejat, H., "Nanoscale friction as a function of activation energies", Surface Topography: Metrology and Properties, 2015, 3 (4), pp. 44002.

[12] Buzio, R., Boragno, C., Valbusa, U., "Friction laws for lubricated nanocontacts", The Journal of Chemical Physics, 2006, 125 (9), pp. 94708.

[13] Krasowska, M., Popescu, M.N., Ralston, J., "Hydrodynamics in nanoscale confinement: SFA and colloid probe AFM liquid drainage experiments", Journal of Physics: Conference Series, 2012, 392 (1), pp. 012009.

[14] Bhushan, B., Fundamentals of tribology and bridging the gap between the macro-and micro/nanoscales, Springer Science \& Business Media, 2012.

[15] Umer, J., Morris, N., Rahmani, R., Rahnejat, H., Balakrishnan, S., Interaction of dispersants with anti-wear and friction modifiers in contacts representative of piston- 
ring liner interface, in: 3rd Int. Brazilian Conf. Tribol. - TriBoBR 2018, 2018.

[16] Umer, J., Morris, N., Leighton, M., Rahmani, R., Balakrishnan, S., Rahnejat, H., "Nano and microscale contact characteristics of tribofilms derived from fully formulated engine oil", Tribology International, 2019, 131 pp. 620-630.

[17] Umer, J., Morris, N., Leighton, M., Rahmani, R., Rahnejat, H., Howell-Smith, S., Balakrishnan, S., Nano-scale Investigation of frictional characteristics of tribo-films in sliding contacts of representative in-cylinder conditions, in: 6th World Tribol. Congr., Loughborough University, 2017.

[18] Leighton, M., Nicholls, T., De La Cruz, M., Rahmani, R., Rahnejat, H., "Combined lubricant-surface system perspective: Multi-scale numerical-experimental investigation", Proc IMechE Part J: J Engineering Tribology, 2016, 0 (0), pp. 1-15.

[19] Chong, W., Ng, J.-H., "An atomic-scale approach for biodiesel boundary lubricity characterisation", International Biodeterioration \& Biodegradation, 2016, 113 pp. 3443 .

[20] Taylor, Hu, H., Stow, C., Davenport, T., Mainwaring, R., Rappaport, S., Remmert, S., Extending the Limits of Fuel Economy through Lubrication, in: SAE Tech. Pap. 201701-2344, 2017.

[21] Rudnick, L., Lubricant additives : chemistry and applications, 2nd Ed., CRC Press, Boca Raton, 2009.

[22] Barnes, A.M., Bartle, K.D., Thibon, V.R.A., "A review of zinc dialkyldithiophosphates (ZDDPS): characterisation and role in the lubricating oil", Tribology International, 2001, 34 (6), pp. 389-395.

[23] Inoue, K., Watanabe, H., "Interactions of Engine Oil Additives", A S L E Transactions, 1983, 26 (2), pp. 189-199.

[24] Barcroft, F.T., Park, D., "Interactions on heated metal surfaces between zinc dialkyldithiophosphates and other lubricating oil additives", Wear, 1986, 108 (3), pp. 213-234.

[25] Ratoi, M., Castle, R.C., Bovington, C.H., Spikes, H.A., "The influence of soot and dispersant on ZDDP film thickness and friction", Lubrication Science, 2004, 17 (1), pp. $25-43$.

[26] Usman, M., Saleem, M.W., Saqib, S., Umer, J., Naveed, A., Hassan, Z.U., "SI engine performance, lubricant oil deterioration, and emission: A comparison of liquid and gaseous fuel", Advances in Mechanical Engineering, 2020, 12 (6), pp. 1-11.

[27] Maharaj, D., Bhushan, B., "Characterization of nanofriction of MoS2 and WS2 nanotubes", Materials Letters, 2015, 142 pp. 207-210.

[28] Koinkar, V.N., Bhushan, B., "Effect of scan size and surface roughness on microscale friction measurements", Journal of Applied Physics, 1997, 81 (6), pp. 2472-2479.

[29] Carpick, Agraï, N., Ogletree, D.F., Salmeron, M., "Measurement of interfacial shear (friction) with an ultrahigh vacuum atomic force microscope", Journal of Vacuum Science \& Technology B: Microelectronics and Nanometer Structures, 1996, 14 (2), 
pp. 1289.

[30] Gosvami, N.N., Bares, J.A., Mangolini, F., Konicek, A.R., Yablon, D.G., Carpick, R.W., "Mechanisms of antiwear tribofilm growth revealed in situ by single-asperity sliding contacts", Science, 2015, 348 (6230), pp. 102-105.

[31] Gosvami, N.N., Lahouij, I., Ma, J., Carpick, R.W., "Nanoscale in situ study of ZDDP tribofilm growth at aluminum-based interfaces using atomic force microscopy", Tribology International, 2020, 143 pp.

[32] Chong, W., Teodorescu, M., Rahnejat, H., "Nanoscale elastoplastic adhesion of wet asperities", Proceedings of the Institution of Mechanical Engineers, Part J: Journal of Engineering Tribology, 2013, 227 (9), pp. 996-1010.

[33] Nikhil, S.T., "Scale dependence of micro/ nano-friction and adhesion of mems/ nems materials, coatings and lubricants", Nanotechnology, 2004, 15 (11), pp. 1561-1570.

[34] Briscoe, B.J., Tabor, D., "Shear Properties of Thin Polymeric Films", The Journal of Adhesion, 1978, 9 (2), pp. 145-155.

[35] Blodgett, K.B., Langmuir, I., "Built-Up Films of Barium Stearate and Their Optical Properties", Physical Review, 1937, 51 (11), pp. 964-982.

[36] Ewen, J., Kannam, S., Todd, B., Dini, D., "Slip of alkanes confined between surfactant monolayers adsorbed on solid surfaces", Langmuir, 2018, 34 (13), pp. 3864-3873.

[37] Tambe, N.S., Bhushan, B., "Friction model for the velocity dependence of nanoscale friction", Nanotechnology, 2005, 16 (10), pp. 2309.

[38] Furlong, O.J., Manzi, S.J., Martini, A., Tysoe, W.T., "Influence of Potential Shape on Constant-Force Atomic-Scale Sliding Friction Models", Tribology Letters, 2015, 60 (2), pp. 21.

[39] Tomlinson, G.A., "A molecular theory of friction", The London, Edinburgh, and Dublin Philosophical Magazine and Journal of Science, 1929, 7 (46), pp. 905-939.

[40] Spikes, H., Tysoe, W., "On the Commonality Between Theoretical Models for Fluid and Solid Friction, Wear and Tribochemistry", Tribology Letters, 2015, 59 (1), pp. 21.

[41] Eyring, H., "Viscosity, Plasticity, and Diffusion as Examples of Absolute Reaction Rates", The Journal of Chemical Physics, 1936, 4 (4), pp. 283-291.

[42] Umer, J., Morris, N., Rahmani, R., Balakrishnan, S., Rahnejat, H., "Nanoscale frictional characterisation of base and fully formulated lubricants based on activation energy components", Tribology International, 2020, 144 (106115), pp.

[43] Alam, K., Umer, J., Iqbal, M., Hasan, A., "Measurements of Elastic Properties of Biological Hydrogels using Atomic Force Microscopy - IOPscience", Journal of Physics: Conference Series, 2020, 1455 pp.

[44] Umer, J., Morris, N., Leighton, M., Rahmani, R., Howell-Smith, S., Wild, R., Rahnejat, H., "Asperity level tribological investigation of automotive bore material and coatings", Tribology International, 2018, 117 pp. 131-140. 
[45] Umer, J., A multiscale, integrated experimental-analytical approach to mitigate boundary friction using lubricant-surface system perspective, 2020, Loughborough University. Thesis. 10.26174/THESIS.LBORO.11647716.V1.

[46] Bouhacina, T., Aimé, J.P., Gauthier, S., Michel, D., Heroguez, V., "Tribological behavior of a polymer grafted on silanized silica probed with a nanotip", Physical Review B, 1997, 56 (12), pp. 7694-7703.

[47] Ku, I.S.Y., Chong, W.W.F., Reddyhoff, T., Rahnejat, H., "Frictional characteristics of molecular length ultra-thin boundary adsorbed films", Meccanica, 2015, 50 (7), pp. 1915-1922.

[48] Müser, M.H., "Velocity dependence of kinetic friction in the Prandtl-Tomlinson model", Physical Review B, 2011, 84 (12), pp. 125419.

[49] Briscoe, B.J., Evans, D.C.B., "The Shear Properties of Langmuir-Blodgett Layers", Proceedings of the Royal Society of London.Series A, Mathematical and Physical Sciences, 1982, 380 (1779), pp. 389-407.

[50] Maugis, D., "Adhesion of spheres: The JKR-DMT transition using a dugdale model", Journal of Colloid and Interface Science, 1992, 150 (1), pp. 243-269.

[51] Derjaguin, B.., Muller, V.., Toporov, Y.., "Effect of contact deformations on the adhesion of particles", Journal of Colloid and Interface Science, 1975, 53 (2), pp. 314 326.

[52] Johnson, K.L., Kendall, K., Roberts, A.D., Johnsont, K.L., "Surface Energy and the Contact of Elastic Solids", Proceedings of the Royal Society of London. Series A, Mathematical and Physical Sciences, 1971, 324 pp. 301-313.

[53] Bradley, R.S., "LXXIX. The cohesive force between solid surfaces and the surface energy of solids", The London, Edinburgh, and Dublin Philosophical Magazine and Journal of Science, 1932, 13 (86), pp. 853-862.

[54] Hertz, H., "über die Berührung Fester Elastischer Korper", Journal Für Die Reine Und Angewandte Mathematik, 1881, 92 pp. 156-171.

[55] Gohar, R., Rahnejat, H., Fundamentals of tribology, World Scientific, 2012.

[56] Hamdan, S.H., Chong, W.W.F., Ng, J.-H., Chong, C.T., Zhang, H., "Nano-tribological characterisation of palm oil-based trimethylolpropane ester for application as boundary lubricant", Tribology International, 2018, 127 pp. 1-9.

[57] Spikes, H., "Stress-augmented thermal activation: Tribology feels the force", Friction, 2018, 6 (1), pp. 1-31.

[58] Hirst, W., Moore, A.J., "Elastohydrodynamic lubrication at high pressures - 2. nonnewtonian behavior", Proc R Soc London Ser A, 1979, 365 (1723), pp. 537-565.

[59] Tung, S.C., McMillan, M.L., "Automotive tribology overview of current advances and challenges for the future", Tribology International, 2004, 37 (7), pp. 517-536.

[60] Ruan, J., Bhushan, B., "Atomic-scale and microscale friction studies of graphite and diamond using friction force microscopy", Journal of Applied Physics, 1994, 76 (9), 
pp. 5022-5035.

[61] Carpick, Agraï, N., Ogletree, D.F., Salmeron, M., "Variation of the Interfacial Shear Strength and Adhesion of a Nanometer-Sized Contact", Langmuir, 1996, 12 (13), pp. 3334-3340.

[62] Landman, U., Luedtke, W.D., Nitzan, A., "Dynamics of tip-substrate interactions in atomic force microscopy", Surface Science Letters, 1989, 210 (3), pp. L177-L184.

[63] Campen, S., Green, J.H., Lamb, G.D., Spikes, H.A., "In Situ Study of Model Organic Friction Modifiers Using Liquid Cell AFM; Saturated and Mono-unsaturated Carboxylic Acids", Tribology Letters, 2015, 57 (2), pp. 18.

[64] Buenviaje, C.K., Ge, S.-R., Rafailovich, M.H., Overney, R.M., "Atomic Force Microscopy Calibration Methods for Lateral Force, Elasticity, and Viscosity", MRS Proceedings, 1998, 522 pp. 187.

[65] Styles, G., Rahmani, R., Rahnejat, H., Fitzsimons, B., "In-cycle and life-time friction transience in piston ring-liner conjunction under mixed regime of lubrication", International Journal of Engine Research, 2014, 15 (7), pp. 862-876.

[66] Pereira, G., Lachenwitzer, A., Kasrai, M., Bancroft, G.M., Norton, P.R., Abrecht, M., Gilbert, P.U.P.A., Regier, T., Blyth, R.I.R., Thompson, J., "Chemical and mechanical analysis of tribofilms from fully formulated oils Part 1 - Films on 52100 steel", Tribology - Materials, Surfaces \& Interfaces, 2007, 1 (1), pp. 48-61.

[67] Forder, M., Umer, J., Morris, N., Rahmani, R., Howell-Smith, S., Rahnejat, H., "Asperity level frictional interactions of cylinder bore materials and lubricant composition", Proceedings of the Institution of Mechanical Engineers, Part J: Journal of Engineering Tribology, 2020, 0 (0), pp. 1-8.

[68] Ahimou, F., Semmens, M.J., Novak, P.J., Haugstad, G., "Biofilm cohesiveness measurement using a novel atomic force microscopy methodology.", Applied and Environmental Microbiology, 2007, 73 (9), pp. 2897-904.

[69] Tambe, N.S., Bhushan, B., "A new atomic force microscopy based technique for studying nanoscale friction at high sliding velocities", Journal of Physics D: Applied Physics, 2005, 38 (5), pp. 764-773.

[70] Nečas, D., Klapetek, P., "Gwyddion: an open-source software for SPM data analysis", Open Physics, 2011, 10 (1), pp. 181-188.

[71] Ruan, Bhushan, B., "Atomic-Scale Friction Measurements Using Friction Force Microscopy: Part I-General Principles and New Measurement Techniques", Journal of Tribology, 1994, 116 (2), pp. 378.

[72] Overney, R.M., Takano, H., Fujihira, M., Meyer, E., Güntherodt, H.J., "Wear, friction and sliding speed correlations on Langmuir-Blodgett films observed by atomic force microscopy", Thin Solid Films, 1994, 240 (1-2), pp. 105-109.

[73] Tambe, N.S., Bhushan, B., "Friction model for the velocity dependence of nanoscale friction", Nanotechnology, 2005, 16 (10), pp. 2309-2324.

[74] Bhushan, B., Handbook of Nanotechnology, 2nd ed., Springer, Columbus OH USA, 
2017.

[75] Thornton, J., "Scanning Probe Microscopy Training Notebook", Santa Barbra, Ca: Veeco Metrology Group, 2000, pp. 1-56.

[76] Fusco, C., Fasolino, A., "Velocity dependence of atomic-scale friction: A comparative study of the one- and two-dimensional Tomlinson model", Physical Review B, 2005, 71 (4), pp. 045413.

[77] He, M., Szuchmacher Blum, A., Overney, G., Overney, R.M., "Effect of Interfacial Liquid Structuring on the Coherence Length in Nanolubrication", Physical Review Letters, 2002, 88 (15), pp. 154302.

[78] Bhushan, B., Israelachvili, J.N., Landman, U., "Nanotribology: friction, wear and lubrication at the atomic scale", Nature, 1995, 374 (6523), pp. 607-616.

[79] Kumar, A., Staedler, T., Jiang, X., "Effect of normal load and roughness on the nanoscale friction coefficient in the elastic and plastic contact regime", Beilstein Journal of Nanotechnology, 2013, 4 (1), pp. 66-71.

[80] Spikes, H., "The History and Mechanisms of ZDDP", Tribology Letters, 2004, 17 (3), pp. 469-489.

[81] Gittens, R.A., McLachlan, T., Olivares-Navarrete, R., Cai, Y., Berner, S., Tannenbaum, R., Schwartz, Z., Sandhage, K.H., Boyan, B.D., "The effects of combined micron/submicron-scale surface roughness and nanoscale features on cell proliferation and differentiation", Biomaterials, 2011, 32 (13), pp. 3395-3403. 